\title{
ESTUDO DA PRECIPITAÇÃO NO ESTADO DE MINAS GERAIS-MG
}

\author{
SILVA, Esmeraldo David da - esmeranegro@gmail.com \\ REBOITA, Michelle Simões - reboita@gmail.com \\ Instituto de Recursos Naturais, Universidade Federal de Itajubá - UNIFEI
}

\begin{abstract}
RESUMO: Com o objetivo de realizar uma caracterização da precipitação no Estado de Minas Gerais (MG), foram utilizados dados diários de precipitação, entre 1990 a 2009, de 335 postos pluviométricos (PP) do sítio da Agência Nacional de Águas (ANA). Determinaram-se (a) as médias mensais, sazonais e anual da precipitação, (b) a possível influência do fenômeno El Niño-Oscilação Sul (ENOS) na precipitação sazonal e (c) a identificação do início e fim da estação chuvosa em MG. Entre os resultados tem-se que os maiores totais de precipitação ocorrem no verão e os menores no inverno e que o setor sul do Estado é o mais úmido. A fase positiva do ENOS (El Niño) não possui influência significativa na precipitação em MG, enquanto que a fase negativa (La Niña) tende a reduzir a precipitação no verão em grande parte do Estado. Em geral, a estação chuvosa em MG inicia entre os dias 13 a 17 de outubro e termina entre os dias 22 a 26 de março.
\end{abstract}

Palavras-Chave: precipitação, estação chuvosa, Estado de Minas Gerais PRECIPITATION ESTUDY FOR MINAS GERAIS STATE, BRAZIL

ABSTRACT: In order to perform a characterization of the precipitation in Minas Gerais (MG) State, we used daily rainfall data, from 1990 to 2009, of 335 rain gauges (RG) of the "Agência Nacional de Águas" (ANA). We determined (a) the monthly, seasonal and annual rainfall average, (b) the possible influence of El Niño-Southern Oscillation (ENSO) in seasonal precipitation and (c) the identification of the onset and demise of the rainy season in MG. Among the results, it was verified that the largest total rainfall occurs in summer and the lowest in winter and the southern sector of the state is more humid. The positive phase of ENSO (EI Niño) has no significant influence on rainfall in MG, while the negative phase ( $L a \mathrm{Niña}$ ) tends to reduce rainfall in summer. In general, in MG the rainy season starts between 13 to October 17 and ends between 22 to March 26.

Keywords: precipitation, rainy season, Minas Gerais State

\section{INTRODUÇÃO}

A precipitação é uma das variáveis atmosféricas mais estudadas, pois o conhecimento da sua variabilidade espacial e temporal permite o planejamento das atividades humanas. São vários os setores que dependem diretamente do conhecimento do regime pluviométrico, por exemplo, a agricultura, o setor energético, entre outros. Um problema devido ao déficit de precipitação no Brasil que vale a pena ser mencionado foi o ocorrido no ano de 2001: a escassez de chuvas aliada à mudança estrutural do setor energético com o processo de privatização culminou na ocorrência do chamado apagão, gerando racionamento de energia em todo o país (GOMES, 2007).

Com relação ao Estado de Minas Gerais (MG), há alguns estudos que apresentam a distribuição espacial da chuva, mas incluindo poucos Postos Pluviométricos (PP) e dados que não se estendem até o presente. Um exemplo que pode ser citado é o estudo de Souza et al. (2011) que utilizaram as Normais Climatológicas (NC) de 1961 a 1990, de 57 estações meteorológicas, 
determinadas pelo Instituto Nacional de Meteorologia (INMET, 2009) para avaliarem a homogeneidade espaço-temporal das chuvas em MG. Também são poucos os estudos que enfocam a relação do fenômeno El Niño-Oscilação Sul (ENOS) com as chuvas na região sudeste do Brasil. Minuzzi et al. (2006) estudaram a relação do El Niño (EN) com a precipitação na região sudeste durante o verão e não obtiveram influencia desse fenômeno na precipitação. Coelho et al. (1999) avaliaram a influência do ENOS em todo o Brasil com dados de 206 estações meteorológicas do INMET, entre 1963 e 1998. Os autores verificaram que só no verão durante a fase negativa do ENOS (La Niña) há anomalias negativas de precipitação significativas em MG.

De acordo com Vera et al. (2006), Reboita et al. (2010) e Marengo et al. (2012), o Estado de MG se localiza no setor da América do Sul (AS) que é influenciado pelo regime de Monção Sul-Americana (MSA). Segundo Vera et al. (2006), a MSA inicia sua fase úmida no final de setembro e início de outubro, atinge a maturidade entre o final de novembro e final de fevereiro e decai entre março e abril. O ciclo de vida da MSA (início, fim e duração da estação chuvosa) é, em geral, identificado com metodologias que fazem o uso de pêntadas (totais ou médias de alguma variável meteorológica em períodos de 5 dias). Kousky (1988), utilizando pêntadas de radiação de onda longa emergente sobre todo o Brasil, mostrou que o início da estação chuvosa em MG e cercanias ocorre entre as pêntadas 54 e 58 (23 de setembro a 17 de outubro), o final entre as pêntadas 19 e 21 ( 1 a 15 de abril) e tem duração de aproximadamente 35 a 39 pêntadas ou 175-195 dias. Já Bombardi e Carvalho (2008), através de pêntadas de precipitação determinadas no período de 1979-2004, verificaram que a duração da estação chuvosa em MG é de cerca de 34 pêntadas (170 dias) e que seu início ocorre entre as pêntadas 56 e 60 (3 a 27 de outubro). Minuzzi et al. (2007) constataram que o início da estação chuvosa no setor sul de MG ocorre entre as pêntadas 54 e 55 (23 de setembro a 2 de outubro) e no setor norte entre as pêntadas 60 e 62 (23 de outubro a 2 de novembro); já o final da estação chuvosa no setor sul é entre as pêntadas 16 e 20 (17 de março a 10 de abril) e no setor norte é entre as pêntadas 14 e 20 ( 7 de março a 10 de abril) Esmeraldo me mande a parte do artigo que mostra essa informação. Com relação à duração do período chuvoso, no setor sul é de 173 a 192 dias (35 a 38 pêntadas) e no setor norte de 136 a 155 dias (27 a 31 pêntadas).

Tendo em vista que são escassos os trabalhos sobre precipitação no Estado de MG utilizando um grande número de PP e com dados estendendo-se até o presente, o objetivo deste estudo é a determinação das características médias da precipitação em MG, incluindo dados de um grande número de PP (335) da Agência Nacional de Águas (ANA) e mais atuais (entre 1990 a 2009). Também será avaliado se o fenômeno ENOS exerce influência na precipitação sazonal. Por fim, é apresentada uma análise do ciclo de vida da estação chuvosa em MG. 


\section{MATERIAIS E MÉTODOS}

\section{Área de estudo}

A área de estudo é o Estado de MG, localizado entre os paralelos 14013'58" e

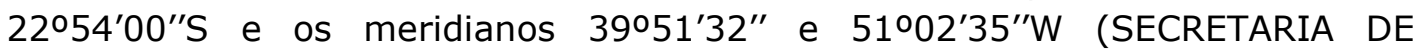
ESTADO DE TURISMO DE MG, 2012). MG cobre uma área de 586.528,293 km², possui 19.595.309 habitantes e é o segundo Estado mais populoso do país (IBGE, 2010).

\section{Dados de precipitação}

Foram utilizados dados diários de precipitação obtidos no sítio da ANA (http://hidroweb.ana.gov.br/). Inicialmente, obtiveram-se as séries temporais de 1134 PP distribuídos por todo o Estado de MG (Figura 1a). Como os PP começaram a funcionar em períodos diferentes e, atualmente, alguns se encontram desativados e outros em operação, foi necessário encontrar um período comum de dados entre esses postos e que incluísse os anos mais próximos do presente. Seguindo esses pressupostos foram selecionados 389 PP com dados entre o ano de 1990 e 2009. Após os dados terem passado por um controle de qualidade (ver próximos itens), 54 PP foram descartados, restando 335 PP para o respectivo trabalho (Figura $\mathbf{1 b}$ ).

a)

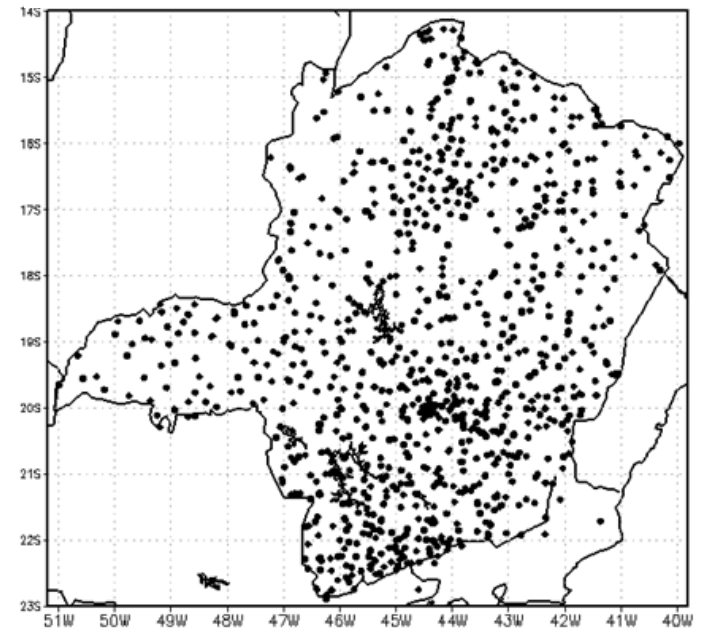

b)

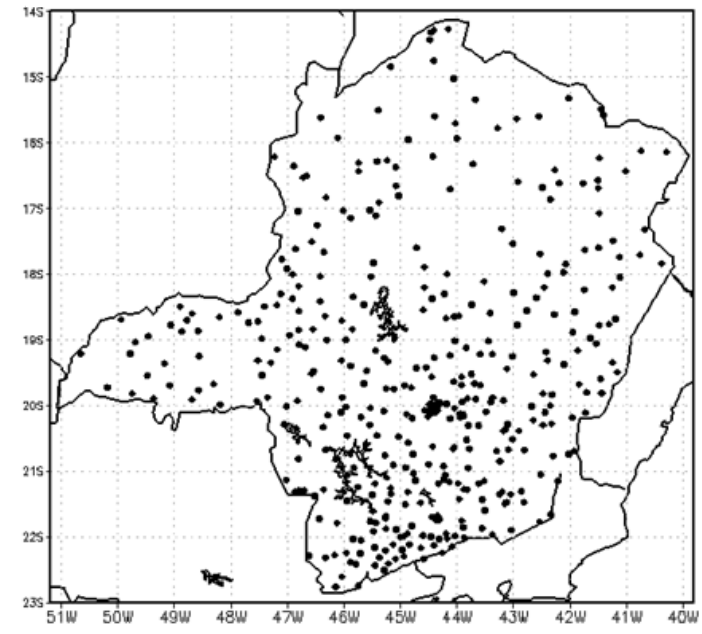

Figura 1 Distribuição dos 1334 PP (a) e 335 PP (b) no Estado de MG.

\section{Controle de qualidade dos dados de precipitação}

Inicialmente, foi realizada uma busca por dados errôneos nas séries temporais de precipitação. Dados errôneos são aqueles valores que uma determinada variável não pode assumir. Por exemplo, a ocorrência de um total de precipitação de $1000 \mathrm{~mm}$ ao longo de 24 horas. Sugahara et al. (2011) sugere a criação de um limiar superior para a identificação de possíveis dados errôneos 
nas séries temporais de precipitação baseado na estatística da Variação Interquartil (Interquartile Range, IQR):

$$
\mathrm{n}=\mathrm{Q}_{98 \%}+3 \mathrm{IQR}
$$

onde $\mathrm{Q}_{98 \%}$ é o percentil de $98 \%$ e IQR é, simplesmente, a diferença entre os quartis superior $\left(Q_{75 \%}\right)$ e inferior $\left(Q_{25 \%}\right)$ de uma série de dados (WILKS, 2006): $\mathrm{IQR}=\mathrm{Q}_{75 \%}-\mathrm{Q}_{25 \%}$.

Os valores maiores do que $\mathrm{n}$ em cada PP foram descartados. Também é interessante lembrar que o menor valor (limiar inferior) que pode ser encontrado numa série de precipitação é zero. Sendo assim, também se procurou por valores menores do que zero.

\section{Teste de homogeneidade}

Na etapa de controle de qualidade dos dados, também é necessário avaliar se as séries temporais são homogêneas, pois a troca de instrumentos, instrumentos mal calibrados, mudança do local do PP, urbanização ao redor do PP, dentre outros, podem afetar as séries temporais criando descontinuidades nos dados. Isso acaba afetando as médias climatológicas sazonais, anuais, etc. Nesse caso, a série deve passar por um processo de homogeneização ou ser descartada. No presente estudo, as séries que não apresentaram homogeneidade foram descartadas.

Para avaliar a homogeneidade das séries temporais foi utilizado Standard Normal Homogeneity Test (SNHT); (ALEXANDERSSON, 1986). Esse teste é recomendado pela World Meteorological Organization (WMO; AGUILAR et al., 2003) e uma descrição do mesmo é fornecida em Toreti et al. (2010), Minuzzi (2010) e Santos (2012), por exemplo. Como mencionado anteriormente, 54 PP não apresentaram homogeneidade e, portanto, foram excluídos. Dessa forma, utilizaram-se 335 PP no estudo (Figura 1b).

\section{Cálculo das médias}

Para cada mês do período em estudo de cada PP foram determinados os totais mensais de precipitação. Se num determinado mês ocorreu à falta de pelo menos um dado diário, já não se teve total mensal de precipitação daquele mês. Após essa etapa, para cada mês de cada ano criou-se uma matriz de dados interpolados espacialmente com o método de interpolação de Cressman (1959). Esse método também é utilizado pelo Centro de Previsão de Tempo e Estudos Climáticos (CPTEC), para criar análises diárias de chuva na AS (CPTEC, 2012). Com base na matriz dos dados interpolados mensalmente foram determinadas as médias mensais e sazonais da precipitação em MG. Consideraram-se os meses de dezembro, janeiro e fevereiro (DJF) como verão; março, abril e maio (MAM) como outono; junho, julho e agosto (JJA) como inverno; e setembro, outubro e novembro (SON) como primavera. 


\section{Relação do ENOS com a precipitação}

Com o objetivo de verificar se as fases positiva (EI Niño - EN) e negativa (La Niña - LN) do ENOS contribuem ou não para o aumento ou redução da chuva no Estado de MG, os dados mensais de precipitação interpolados mensalmente foram separados por estação do ano. Posteriormente, os dados de cada estação do ano foram separados em casos de eventos EN, Neutro (período sem ocorrência de ENOS) e LN com base no Oceanic Niño Index (ONI). Esse índice é obtido através da anomalia de temperatura da superfície do mar (TSM) na região de Niño 3.4 ( $5^{\circ} \mathrm{N}$ - $5^{\circ} \mathrm{S}$ e $120^{\circ}$ - $170^{\circ} \mathrm{W}$ ) e de médias móveis trimestrais (NOAA, 2013). As Tabelas 1 a 4 mostram para cada estação do ano os períodos classificados como EN, Neutro e LN.

A etapa seguinte consistiu do cálculo das médias sazonais da precipitação nas diferentes fases do ENOS e das diferenças EN menos Neutro e LN menos Neutro. Para verificar se as diferenças eram estatisticamente significativas, aplicou-se o teste não paramétrico de Wilcoxon-Mann-Whitney. Este é usado para testar a hipótese nula $\left(\mathrm{H}_{0}\right)$ de que duas amostras independentes provêm de populações com a mesma distribuição (isto é, as duas amostras são idênticas). A hipótese alternativa $\left(\mathrm{H}_{1}\right)$ é a afirmativa de que as duas distribuições são diferentes (TRIOLA, 2005). Considerou-se $\alpha=0,05$ no presente estudo.

Tabela 1 - Ocorrência de eventos El Niño, Neutros e La Niña no verão do período de 1990 a 2010 com base no ONI.

\begin{tabular}{|c|c|}
\hline $\begin{array}{c}\text { Fases do } \\
\text { ENOS }\end{array}$ & $\begin{array}{r}\text { Verão: Dezembro (D) / ano antes - Janeiro e Fevereiro } \\
(\mathbf{J}, F) / \text { Ano seguinte }\end{array}$ \\
\hline EI Niño & $\begin{array}{r}\text { D1991/JF1992, D1994/JF1995, D1997/JF1998, D2002/JF2003, } \\
\text { D2004/JF2005, D2006/JF2007 }\end{array}$ \\
\hline Neutro & $\begin{array}{r}\text { D1990/JF1991, D1992/JF1993, D1993/JF1994, D1996/JF1997, } \\
\text { D2001/JF2002, D2003/JF2004, D2008/JF2009 }\end{array}$ \\
\hline La Niña & $\begin{array}{r}\text { D1995/JF1996, D1998/JF1999, D1999/JF2000, D2000/JF2001, } \\
\text { D2005/JF2006, D2007/JF2008 }\end{array}$ \\
\hline
\end{tabular}

Tabela 2 - Similar a tabela 1 , mas para o outono.

\begin{tabular}{|c|c|}
\hline $\begin{array}{c}\text { Fases do } \\
\text { ENOS }\end{array}$ & Outono: Março, Abril e Maio (M, A, M) \\
\hline EI Niño & 1992,1998 \\
\hline Neutro & $1990,1991,1993,1994,1995,1996,1997,2001,2001,2003$, \\
& $2004,005,2006,2007,2009$ \\
\hline La Niña & $1999,2000,2008$ \\
\hline
\end{tabular}


Tabela 3 - Similar a tabela 1 , mas para o inverno.

\begin{tabular}{|c|c|}
\hline $\begin{array}{c}\text { Fases do } \\
\text { ENOS }\end{array}$ & Inverno: Junho, Julho e Agosto (J, J, A) \\
\hline EI Niño & $1991,1997,2002,2004,2009$ \\
\hline Neutro & $1990,1992,1993,1994,1995,1996,2001,2003,2005,2006$, \\
& 2007,2008 \\
\hline La Niña & $1998,1999,2000$ \\
\hline
\end{tabular}

Tabela 4 - Similar a tabela 1, mas para a primavera.

\begin{tabular}{|c|c|}
\hline $\begin{array}{c}\text { Fases do } \\
\text { ENOS }\end{array}$ & Setembro, Outubro e Novembro (S, O, N) \\
\hline EI Niño & $1991,1994,1997,2002,2004,2006,2009$ \\
\hline Neutro & $1990,1992,1993,1996,2001,2003,2005,2008$ \\
\hline La Niña & $1995,1998,1999,2000,2007$ \\
\hline
\end{tabular}

\section{Identificação do início e fim da estação chuvosa em MG}

Para determinar o início e o fim da estação chuvosa em MG era necessário que os PP não possuíssem dados diários faltantes. Entretanto, a maioria dos PP apresentam dados faltantes decorrentes da ausência de registros ou descartados no procedimento de erros grosseiros. Assim, selecionaram-se apenas os PP que apresentaram 20 dados faltantes ou menos entre 1990-2009. Nesta seleção, obtiveram-se 68 PP (Figura 2). Nestes, as falhas foram preenchidas com dados extraídos da análise diária de chuva do Climate Prediction

Center

(ftp://ftp.cpc.ncep.noaa.gov/precip/CPC_UNI_PRCP/GAUGE_GLB/) que tem resolução espacial de $0,5^{\circ} \times 0,5^{\circ}$ de latitude por longitude.

Após a preparação dos dados foram determinadas as pêntadas de chuva para cada PP. As pêntadas correspondem a somatória da precipitação em períodos de 5 dias. A identificação do início e fim da estação chuvosa seguiu a metodologia de Bombardi e Carvalho (2008):

$$
S(\text { pentada })=\sum_{n=\text { pentad } a_{1}}^{\text {pentada }}\left(R_{n}-\bar{R}\right)
$$

onde:

$\mathrm{R}_{\mathrm{n}}$ é a precipitação da pêntada $\mathrm{n}$.

$\overline{\mathrm{R}}$ é a média climatológica de todas as pêntadas em estudo. 
A primeira pêntada apresentada na somatória (pêntada ${ }_{1}$ ) foi escolhida como a primeira pêntada do ano (total da precipitação no período de 1 a 5 de janeiro) que, por sua vez, está dentro da estação chuvosa da região em estudo. Depois de realizado o somatório $S$ para cada pêntada do ano, a série temporal de $S$ foi suavizada com uma média móvel de 3 pontos passada 50 vezes.

A etapa seguinte consistiu do cálculo da primeira derivada de $\mathrm{S}=\mathrm{dS} / \mathrm{dT}$ para a identificação do início e fim da estação chuvosa de cada ano em estudo. A Figura 2 exemplifica o procedimento descrito para o ano de 1991 no PP que está localizado em 14018'49"S e 44027'37"W.

Na Figura 2, a linha azul indica a série temporal de $R_{n}-\bar{R}$, a linha vermelha a série da somatória $S$, a linha verde a séria suavizada de $\mathrm{S}$ e a linha preta a série $\mathrm{de} \mathrm{dS} / \mathrm{dT}$. Inicialmente, $\mathrm{dS} / \mathrm{dT}$ apresenta valores positivos.

Quando a derivada apresentar o seu primeiro valor negativo $(\mathrm{dS} / \mathrm{dT}<0)$ tem-se o início da estação seca no ano de 1990 ou, em outras palavras, o fim da estação chuvosa que iniciou no ano anterior.

A derivada $\mathrm{dS} / \mathrm{dT}$ apresenta uma sequência de valores negativos e quando muda o sinal, ou seja, quando aparece o primeiro valor positivo $(\mathrm{dS} / \mathrm{dT}>0)$ tem-se o início da estação chuvosa do ano em estudo. No exemplo mostrado, a estação seca (ou o fim da estação chuvosa iniciada no ano anterior) começa na pêntada 22 e a estação chuvosa começa na pêntada 56. A tabela que relaciona as pêntadas com as datas ao longo do ano é encontrada em Kousky (1988).

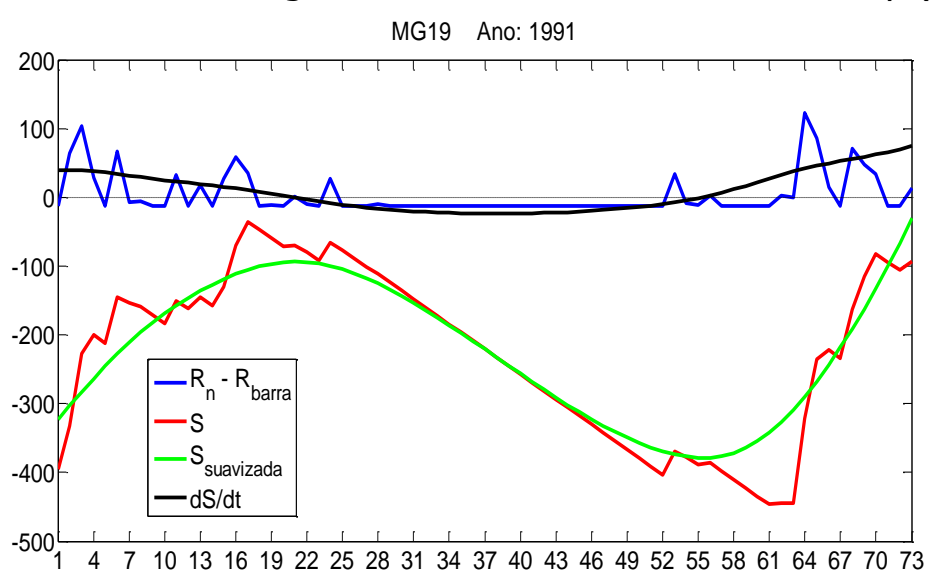

Figura 2 - Exemplo do método utilizado na identificação do início e fim da estação chuvosa no PP localizado na latitude -14.31361111 , longitude -44.46027778 no ano de 1991 .

\section{RESULTADOS E DISCUSSÃO}

\section{Distribuição espacial e temporal da precipitação em MG}

As médias mensais da precipitação entre 1990 a 2009 mostram uma distribuição irregular das chuvas, tanto espacialmente quanto temporalmente 
em MG (Figura 3). Os maiores totais de precipitação encontram-se no centrosul de MG e, em todo o Estado, as chuvas ocorrem principalmente entre outubro a março (figuras 3 j, k, l e 9 a, b, c), o que é similar ao obtido por Mello et al. (2003) e Siqueira et al. (2003). Janeiro é o mês com maior total de precipitação em todo Estado; no Sul de MG o total mensal chega a ultrapassar $350 \mathrm{~mm}$ (figura $3 \mathrm{a}$ ), fato que está associado à grande atividade convectiva da estação e a ocorrência de ZCAS (ABREU, 1998; CARVALHO et al., 2004). Entre abril e outubro (figuras 3 d, e, f e $3 a, b, c, d$ ) há redução das chuvas em MG e o mês de julho se caracteriza como o mais seco, com precipitação abaixo de 40 $\mathrm{mm}$ em todo o estado (figura $3 \mathrm{~g}$ ).
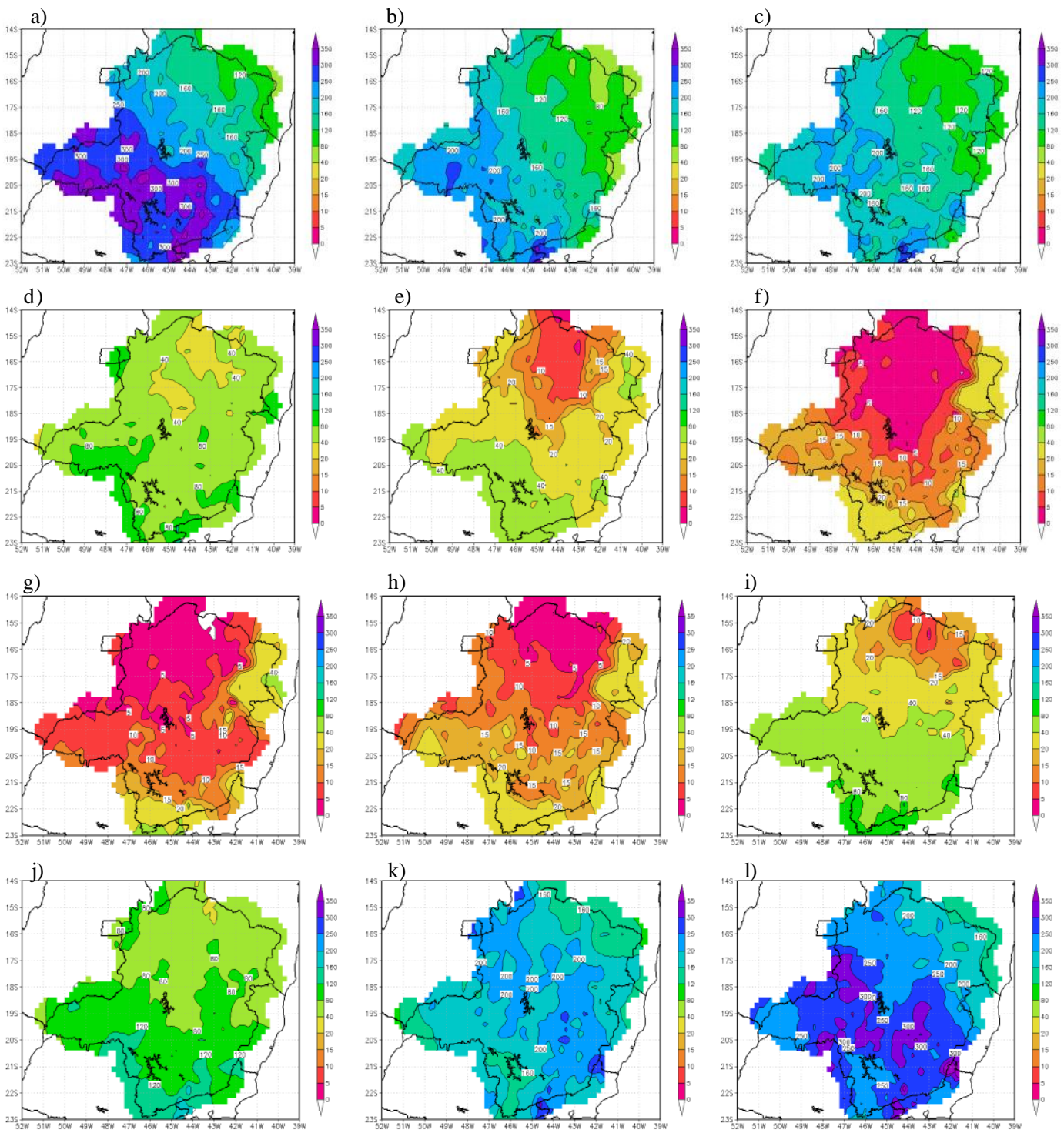

Figura 3 - Média mensal da precipitação em MG entre 1990 a 2009, sendo (a) janeiro, (b) fevereiro, (c) março, (d) abril, (e) maio, (f) junho, (g) julho, (h) agosto, (i) setembro, (j) outubro, (k) novembro e (I) dezembro. 
A análise da média sazonal das chuvas em MG (figura 4) mostra que o verão é a estação mais chuvosa, quando se chega a registrar totais entre $600-800 \mathrm{~mm}$ em áreas do setor sul, parte oeste e região central do Estado; nas áreas mais ao norte de MG a precipitação reduz ficando entre $300-500 \mathrm{~mm}$ (figura 4a). No outono (figura 4b), a precipitação começa a diminuir em relação ao verão e os totais pluviométricos ficam entre $200-350 \mathrm{~mm}$ nos setores sul, centro e oeste de MG; já o norte do Estado apresenta os menores valores nesta estação do ano (100-200 mm). O inverno é o período mais seco do ano em MG, como também apontam outros estudos (exemplo, Tonietto et al., 2006). Os totais pluviométricos do setor sul de MG são de $50-100 \mathrm{~mm}$ e do centro-oeste e do leste de $25 \mathrm{~mm}$ (exceto numa área próxima a região norte em que os valores chegam a $100 \mathrm{~mm}$ ); já no setor norte quase não ocorre precipitação (figura 4c). Na primavera (figura 4d) a precipitação volta a aumentar e são registrados totais pluviométricos de cerca de $200-350 \mathrm{~mm}$ em quase todo Estado, exceto na parte sul onde os totais são mais elevados (350-500 mm). A distribuição espacial da chuva na primavera é similar a do outono (figuras $4 \mathrm{~b}$ e $4 d$ ).
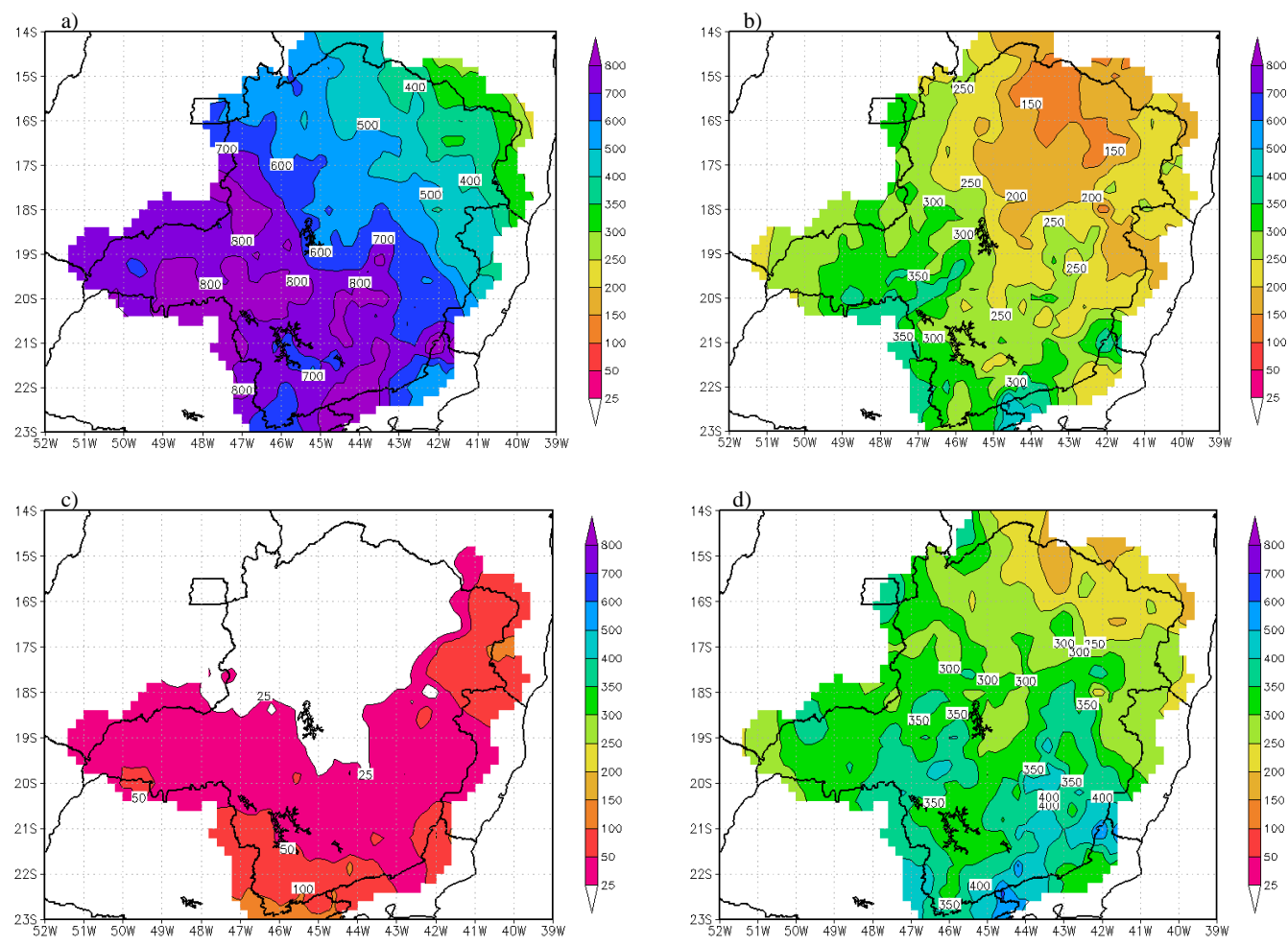

Figura 4 - Média sazonal da precipitação em MG entre 1990 a 2009, sendo (a) verão, (b) outono, (c) inverno, (d) primavera.

Em MG, o verão é a estação mais chuvosa devido à ocorrência da atividade convectiva local e a atuação dos sistemas atmosféricos associados à MSA. A 
MSA está associada com transporte de umidade da Amazônia para os subtrópicos pelo jato de baixos níveis a leste dos Andes, pelo transporte de umidade do oceano Atlântico Sul pelo Anticiclone Subtropical do Atlântico Sul (ASAS) para a região sudeste e também com períodos de atuação da Zona de Convergência do Atlântico Sul (ZCAS), o que contribui para a precipitação em MG. Já no inverno, a convecção local enfraquece, tanto pela redução do aquecimento da superfície quanto pela atuação do setor oeste do ASAS sobre o sudeste do Brasil, o que contribui para o período seco da MSA (Abreu, 1998; Reboita et al., 2010, Marengo et al., 2012).

Com relação à média anual da precipitação (figura 5), os maiores totais anuais (1200-1600 mm) ocorrem nos setores oeste, sul e central de MG; em contrapartida, os setores norte e leste do Estado mostram os menores valores (800-1100 mm e $1000-1200 \mathrm{~mm}$, respectivamente). Esses totais são similares aos de Souza et al. (2006).

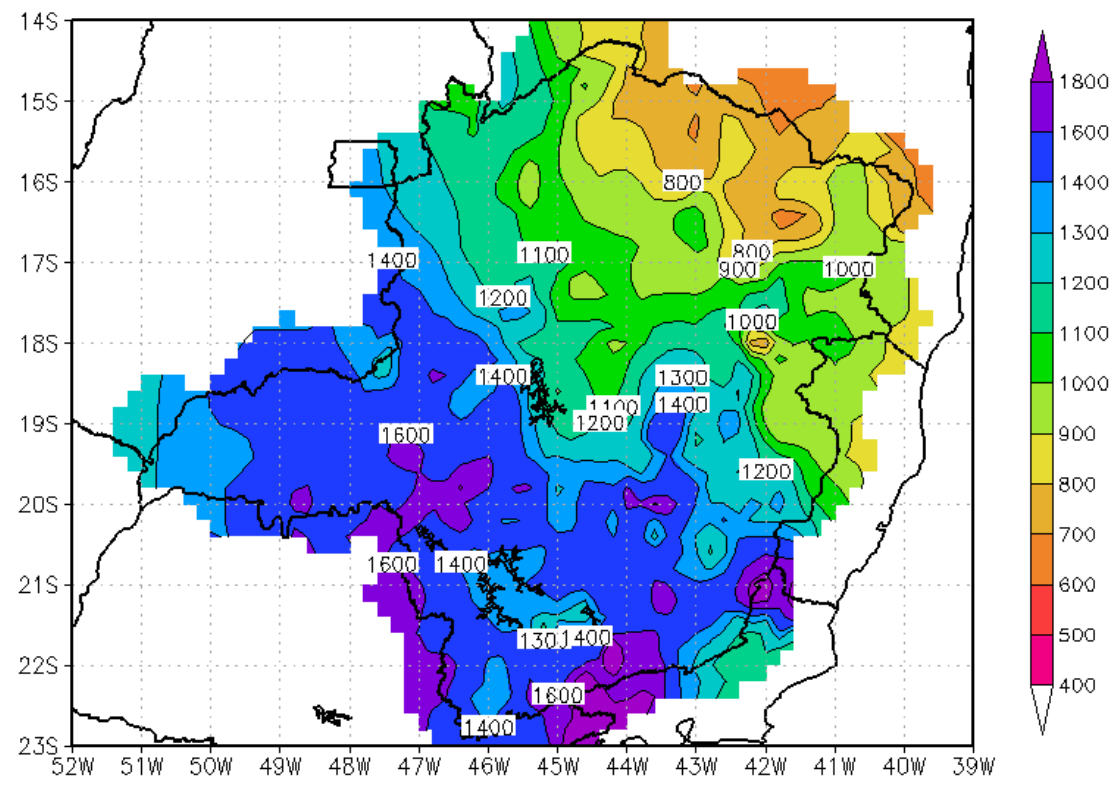

Figura 5 - Média anual da precipitação em MG no período de 1990 a 2009.

\section{Influência dos eventos EI Niño e La Niña na precipitação de MG}

\section{El Niño x Precipitação}

As análises a seguir foram realizadas com base na diferença entre a média sazonal quando ocorreram episódios de EN e a média sazonal dos episódios neutros. Assim, valores positivos (negativos) indicam precipitação maior (menor) do que no período neutro. Na análise do verão (figura 6a) foram incluídos 6 episódios de EN e 7 de anos neutros; no inverno (figura 6c), 5 
episódios de EN e 12 de anos neutros; no outono (figura 6b), 2 episódios de EN e 15 de anos neutros e na primavera (figura 6d), 7 episódios de EN e 8 de anos neutros. O verão e o outono são as estações do ano em que ocorrem as maiores diferenças nos valores de precipitação entre os eventos EN e neutros, porém os resultados não são significativos estatisticamente. No verão há diferenças positivas de $100 \mathrm{~mm}$ no nordeste de MG, enquanto no outono negativas de $100 \mathrm{~mm}$. No inverno e primavera as diferenças nos totais de precipitação entre os anos de EN e neutros diminuem e também não são significativas estatisticamente.
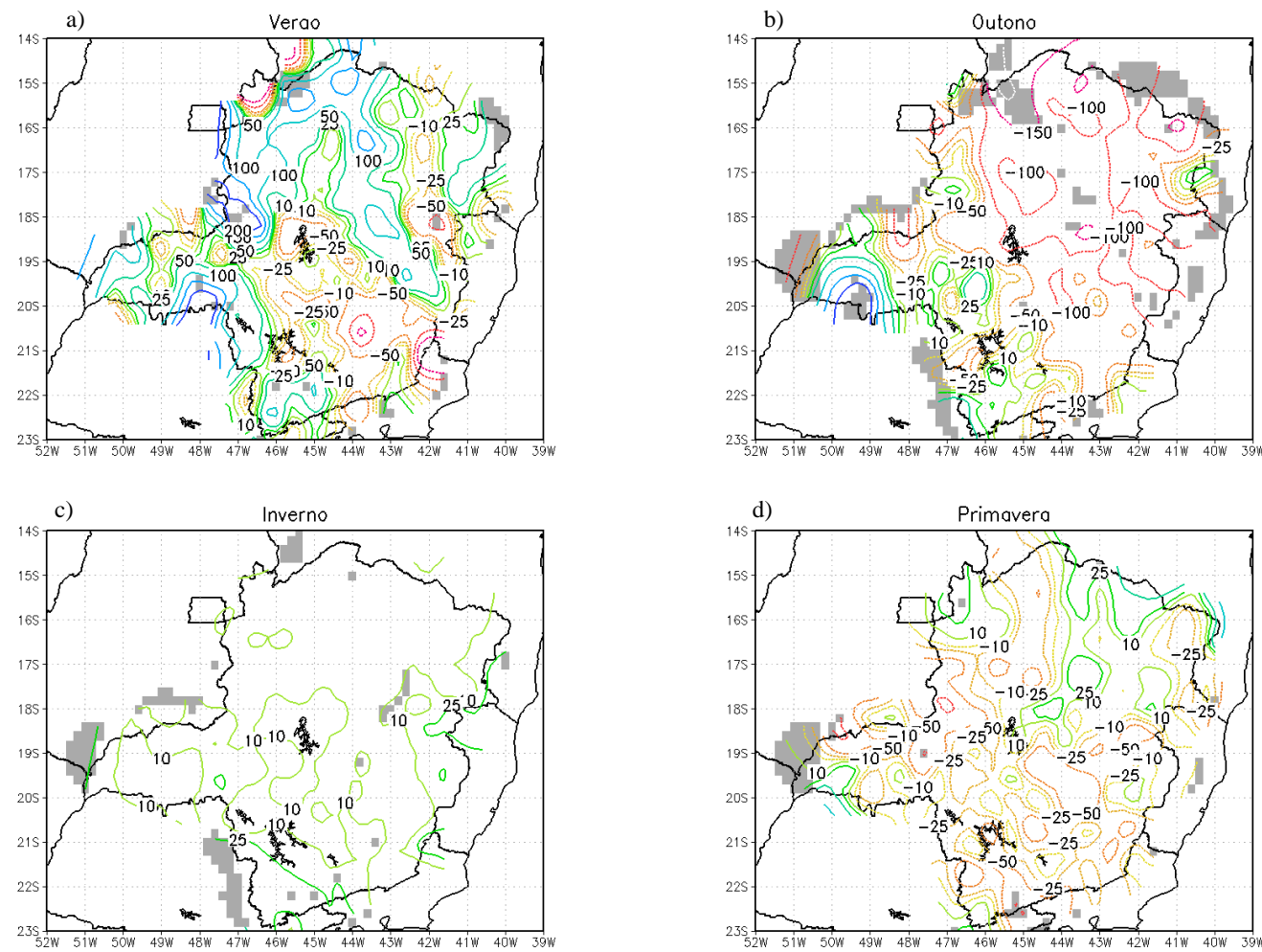

Figura 6 - Diferença entre a média sazonal de precipitação em anos de El Niño e anos neutros (Significância) para MG no período de 1990 a 2009.

\section{La Niña x Precipitação}

Para o verão de LN (figura 7a), as médias foram calculadas utilizando 6 episódios de LN e 7 de anos neutros. Em praticamente todo o Estado de MG ocorreram diferenças negativas $(\sim 200 \mathrm{~mm})$ de precipitação e significativas estatisticamente, o que indica que em anos de LN há redução das chuvas em MG. Esse resultado concorda com Coelho et al. (1999). No outono (figura 7b), as médias incluíram 3 episódios de LN e 15 de anos neutros; no inverno (figura 7c), 3 episódios de LN e 12 de anos neutros, na primavera (figura 7d), 5 episódios de LN e 8 de anos neutros e no verão (figura 7a), 6 casos de LN e 7 de anos neutros. No outono as diferenças entre o total de precipitação entre os eventos de LN e neutros mostraram, em geral, valores positivos de cerca de 50 
mm no centro-sul de MG; já na primavera esses valores tornaram-se negativos e, em ambas as estações, não foram significativos estatisticamente. É interessante ressaltar que o inverno não apresentou diferenças de precipitação.
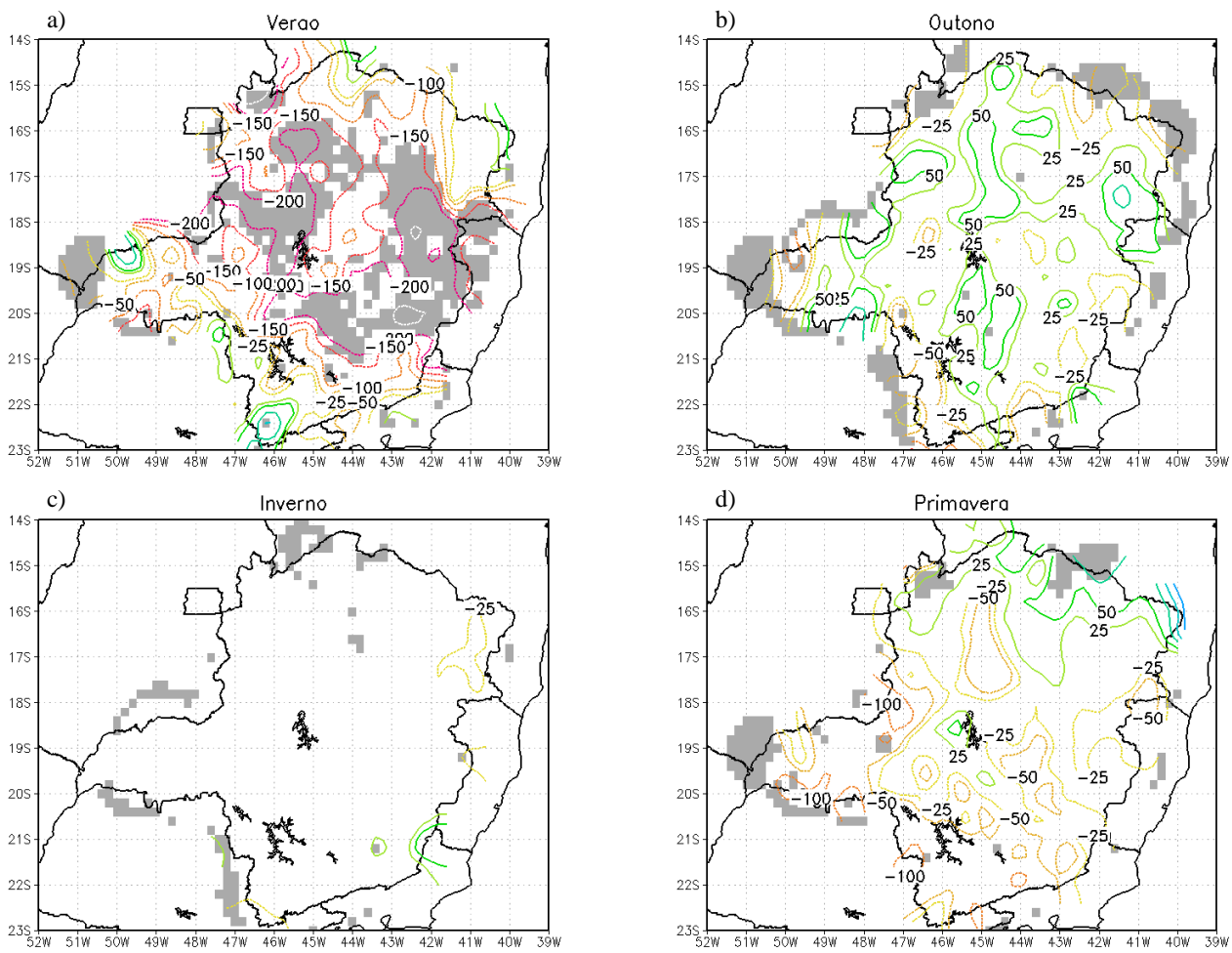

Figura 7 - Diferença entre a média sazonal de precipitação em anos de La Niña e anos neutros (Significância) para MG no período de 1990 a 2009

\section{Identificação do ciclo de vida da estação chuvosa}

\section{Início da estação chuvosa}

A figura 8 mostra a caracterização do início da estação chuvosa em MG. No setor centro-leste, as pêntadas 57 e 58 ( 8 a 17 de outubro) indicam o começo da estação chuvosa e no oeste e norte do Estado, as pêntadas 58 e 59 (13 a 22 de outubro). Essas pêntadas concordam com as obtidas no estudo de Bombardi e Carvalho (2008). De forma geral, a pêntada 58 representa o início da estação chuvosa na maior parte do Estado de MG, exceto na região centro-oeste, onde a pêntada 59 tem maior ocorrência. 


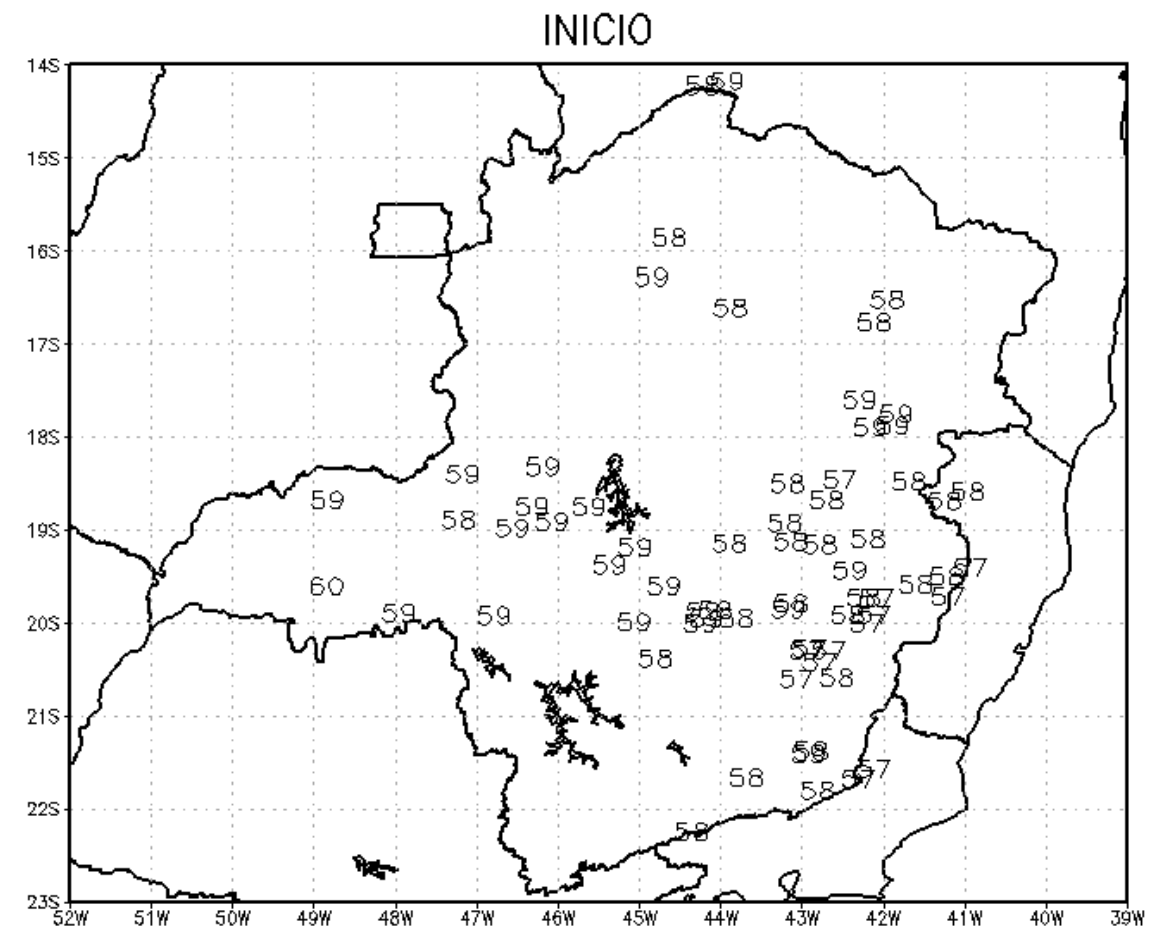

Figura 8 - Início da estação chuvosa em MG. Os valores no mapa correspondem a pêntadas.

\section{Fim da estação chuvosa}

A identificação do fim da estação chuvosa em MG (figura 9) mostra que no setor norte este ocorre entre as pêntadas 15 e 18 (12 a 31 de março); no setor centro-sul e leste têm-se o fim nas pêntadas 16 a 18 (17 a 31 de março) e no setor oeste entre as pêntadas 19 e 20 ( 1 a 10 de abril). Numa média considerando todo o Estado, as pêntadas 17 e 18 representam o fim da estação chuvosa. 


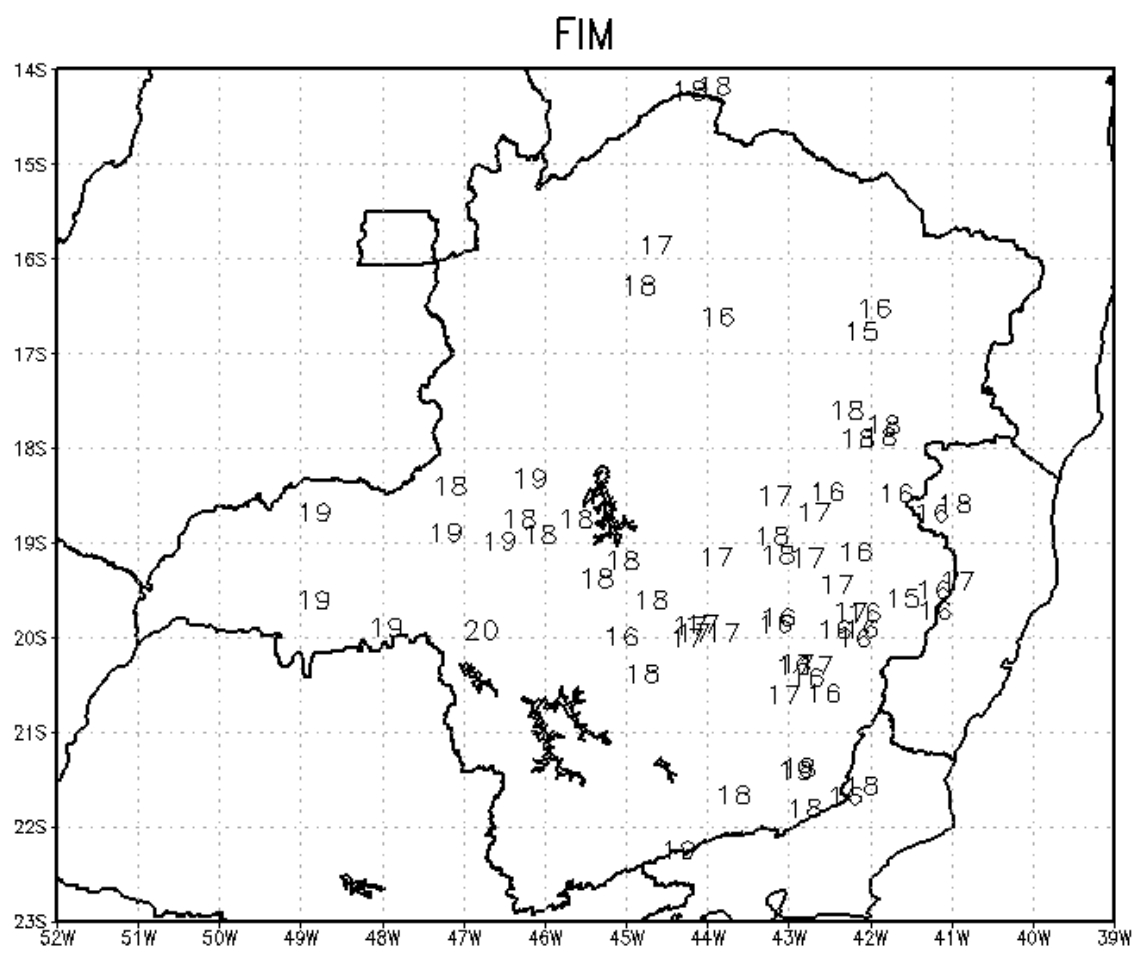

Figura 9 - Fim da estação chuvosa em MG. Os valores no mapa correspondem a pêntadas.

\section{Duração da estação chuvosa}

No setor norte de MG a estação chuvosa tem duração de 31-33 pêntadas (155-165 dias), concordando com Minuzzi et al. (2007). Por outro lado, no centro-sul e leste a estação chuvosa dura cerca de 31-34 pêntadas (155 a 170 dias), o que é similar ao resultado de Bombardi e Carvalho (2008), e no setor oeste, 33-35 pêntadas (165-175 dias). Considerando a média da duração da estação chuvosa em todo o Estado essa é de 33 pêntadas ou 165 dias. 


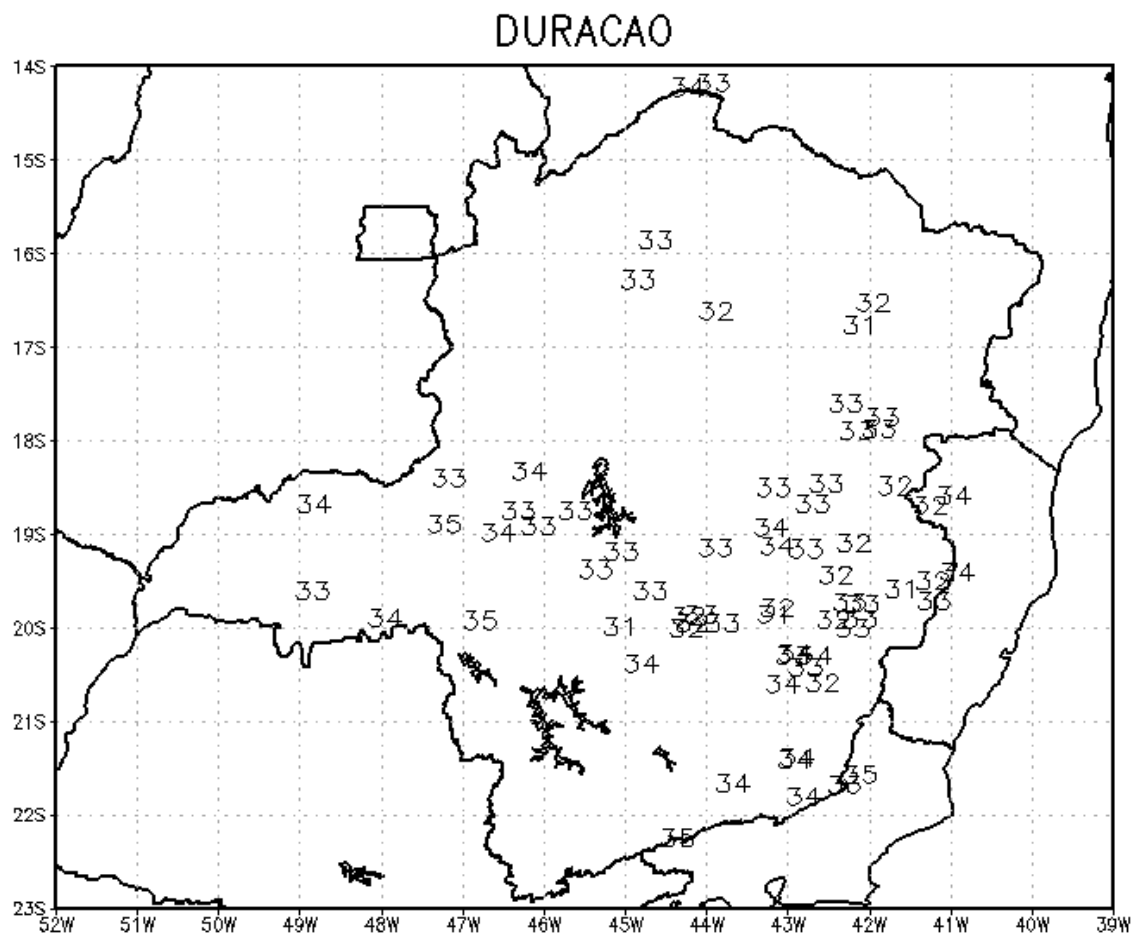

Figura 10 - Duração da estação chuvosa em MG. Os valores no mapa correspondem a pêntadas.

\section{CONCLUSÕES}

Este trabalho apresentou uma caracterização da precipitação em MG, no período de 1990 a 2009. Para tanto, foram utilizados 335 PP da ANA. Em termos médios mensais, os meses entre outubro e março são os mais chuvosos em todo o Estado, sendo que janeiro se destaca com totais ainda mais elevados principalmente no sul do Estado. Já o mês de julho é o mais seco. Considerando a distribuição espacial da chuva em MG, o setor centro-sul é o que apresenta os maiores totais anuais de precipitação enquanto no setor norte são registrados os menores totais.

Em MG, os eventos EN não influenciam significativamente os totais sazonais de precipitação. Por outro lado, os eventos LN causam diferenças negativas significativas estatisticamente na estação do verão, isto é, há diminuição da precipitação nos verões em que ocorrem eventos LN.

De forma geral, o início da estação chuvosa em MG ocorre entre as pêntadas 57 a 59; o final entre as pêntadas 15 a 18 e a duração da estação chuvosa é de cerca de 31 a 35 pêntadas, o que confirma que a época mais chuvosa em MG é entre outubro e março. Por fim, destaca-se que esse estudo contribui para um maior conhecimento das características da precipitação no Estado de MG. 


\section{REFERÊNCIAS BIBLIOGRÁFICAS}

ABREU, M. L. Climatologia da estação chuvosa de Minas Gerais: De Nimer (1977) à Zona de Convergência do Atlântico Sul. GEONOMOS, v.8, n.2, p.17-22, 1998.

AGUILAR, E.; AUER, I.; BRUNET, M.; PETERSON, T.C.; WIERINGA, J. Guidelines on Climate Metadata and Homogenization, World Meteorological Organization (WMO), p. 28-47. 2003.

ALEXANDERSSON, H.A. Homogeneity test applied to precipitation data. Journal of Climatology, v.6, p.661-675, 1986.

BOMBARDI, R. J.; CARVALHO, L. M. V. Variabilidade do regime de monções sobre o Brasil: o clima presente e projeções para um cenário com $2 \times \mathrm{CO} 2$ usando o modelo MIROC. Revista Brasileira de Meteorologia, v.23, n.1, p.58-72, 2008.

CARVALHO, L. M. V.; JONES, C; LIEBMANN, B. The South Atlantic Convergence Zone: persistence, intensity, form, extreme precipitation and relationships with intraseasonal activity. Journal of Climate, v. 17, p. 88-108. , 2004.

CENTRO DE PREVISÃO DE TEMPO E ESTUDOS CLIMÁTICOS (CPTEC). Informações sobre produtos de monitoramento climático da página do CPTEC/INPE, 2012 Cachoeira Paulista, SP. Disponível em: http://www.cptec.inpe.br/

COELHO, C. A. S.; DRUMOND, A. R. M.; AMBRIZZI, T. Estudo climatológico sazonal da precipitação sobre o Brasil em episódios extremos da oscilação sul. Revista Brasileira de Meteorologia, v.14, n. I, p.49-65, 1999.

CRESSMAN, G. P. An operational objective analysis system. Mon. Wea. Rev., v.87, p.367- 374. 1959.

GOMES, V. J. F. O meio ambiente e o risco de apagão no Brasil. In: II SEMINÁRIO INTERNACIONAL: REESTRUTURAÇÃO E REGULAÇÃO DO SETOR DE ENERGIA ELÉTRICA E GÁS NATURAL. Rio de janeiro, 2007. Resumos...Rio de Janeiro. Disponível

em: <http://www.nuca.ie.ufrj.br/gesel/eventos/seminariointernacional/2007/artigos/pdf/ victorjose_omeioambiente.pdf $>$.

INSTITUTO NACIONAL DE METEOROLOGIA (INMET). Normais Climatológicas do Brasil, 1961-1990, 2009, Brasília, DF. Disponível em: http://www.inmet.gov.br/html/clima.php\#

KOUSKY, V. E. Pentad outgoing longwave radiation climatology for the South American sector. Revista Brasileira de Meteorologia., v.3, p.217-231,1988.

MARENGO, J. A.; LIEBMANN, B.; GRIMM, A. M.; MISRA,V.; DIAS, P. L. S.; CAVALCANTI, I. F. A.; CARVALHO, L. M. V.; BERBERY, E. H.; AMBRIZZI,T.; VERA, C. S.; SAULO, A. C.; NOGUES-PAEGLE, J.; ZIPSER, E.; SETH, A.; ALVES, L. M. Review recent developments on the South American monsoon system. International Journal of Climatology, $v$. 32, n. 1, p.1-21, jan. 2012.

MELLO, C. R.; SILVA, A. M.; LIMA, J. M.; FERREIRA, D. F.; OLIVEIRA, M. S. Modelos matemáticos para predição da chuva de projeto para regiões do Estado de Minas Gerais. Revista Brasileira de Engenharia Agrícola e Ambiental, v.7, n.1, p.Jan./Abr. 2003. MINUZZI, R. B.; SEDIYAMA, G. C.; BARBOSA, E. M.; J E. M, J. C. F. M. Climatologia do comportamento do período chuvoso da região sudeste do Brasil. Revista Brasileira de Meteorologia, v.22, n.3, p.338-344, 2007.

MINUZZI, R. B.; SEDIYAMA, G. C.; COSTA, J. M. N.; VIANELLO, R. L. Influência do fenômeno climático El Niño no período chuvoso da região sudeste do Brasil. Geografia, v.15, n.2, jul/dez. 2006.

MINUZZI, R.B. Tendências na variabilidade climática de Santa Catarina, Brasil. Revista Brasileira de Engenharia Agrícola e Ambiental, v.14, n.12, p. 288 - 293, 2010.

REBOITA, M. S.; GAN, M. A.; ROCHA, R. P.; AMBRIZZI, T. Regimes de precipitação na América do Sul: uma revisão bibliográfica. Revista Brasileira de Meteorologia, v. 25, n. 2, p.185-204, jun. 2010.

SANTOS, R. S. Homogeneidade e reconstrução de séries climatológicas para localidades no estado de Minas Gerais. Viçosa, 2012. p. 82. Originalmente apresentada como tese de doutorado, Universidade Federal de Viçosa. 2012. 
SECRETARIA DE ESTADO DE TURISMO DE MINAS GERAIS. Localização Geográfica de Minas Gerais, 2012, Belo Horizonte. Disponível em: http://www.turismo.mg.gov.br/minas-gerais/perfil

SIQUEIRA, H. R.; ALVES, G. F.; GUIMARÃES, E. C. COMPORTAMENTO DA PRECIPITAÇÃO PLUVIOMÉTRICA MENSAL DO ESTADO DE MINAS GERAIS: ANÁLISE ESPACIAL E TEMPORAL. Programa de infra-estrutura para jovens doutores. 2003

SOUZA, L. R. S.; AMANAJÁS, J. C. A.; SILVA, A. P. N.; BRAGA, C. C.; CORREIA, M. F. Determinação de padrões espaço-temporal e regiões homogêneas de precipitação pluvial no estado de Minas Gerais. Engenharia Ambiental, Espírito Santo do Pinhal, v. 8, n. 2, p. 265-280, abr. /jun. 2011.

SOUZA, M. J. H.; GUIMARÃES, M. C. A.; GUIMARÃES, C. D. L.; FREITAS, W.S.; OLIVEIRA, A. M. S. Potencial agroclimático para a cultura da acerola no Estado de Minas Gerais. Revista Brasileira de Engenharia Agrícola e Ambiental. v.10, n.2, p.390396, 2006

SUGAHARA, S.; ROCHA, R.P.; YNOUE, R.Y.; SILVEIRA, R.B. Homogeneity assessment of a station climate series (1933-2005) in the Metropolitan Area of São Paulo: instruments change and urbanization effects. Theor Appl Climatol, 2011.

TONIETTO, J.; VIANELLO, R. L.; REGINA, M.A.; Caracterização macroclimática e potencial enelógico de diferentes regiões com vocação vitícola de Minas Gerais. Informe agropecuário, Belo Horizonte, v.27, n.234, p.32-55, set./out.2006

TORETI, A.; Kuglitsch, F.G.; Xoplaki, E.; Della-Marta, P.M.; Aguilar, E.; Prohom, M.; Luterbacher, J. Short Communication A note on the use of the standard normal homogeneity test to detect inhomogeneities in climatic time series. International Journal Of Climatology. 2010.

TRIOLA, M. Introdução à estatística. Rio de Janeiro: LTC, 2005.

VERA, C.; HIGGINS, W.; AMBRIZZI, T.; AMADOR, J.; GARREAUD, R.; GOCHIS, D.; GUTZLER, D.; LETTENMAIER, D.; MARENGO, J.; MECHOSO, C. R.; NOGUES-PAEGLE.; SILVA DIAS, P. L.; ZHANG, C. Toward a unified view of the American monsoon systems. Journal of Climate, v. 19, n. 20, p. 4977-5000, out. 2006.

WILKS, D. Statistical Methods in the Atmospheric Sciences. $2^{\circ}$ ed. Academic Press. p.627. 2006

WMO no 100,1983 . Guide to Climatological Practices, $2^{\text {a }}$ Ed., Secretariat of the World Meteorological Organization, Geneva. 1983. 